\title{
LOS ELEMENTOS DESCRIPTIVOS COMO TÉCNICA LEGISLATIVA. CONSIDERACIONES CRÍTICAS EN RELACIÓN CON LOS DELITOS DE HURTO Y ROBO CON FUERZA*
}

\author{
María Magdalena Ossandón Widow**
}

\begin{abstract}
RESUMEN
La técnica legislativa empleada en la redacción de una disposición penal debe ser especialmente cuidadosa para lograr los objetivos propuestos y respetar los limites que se imponen a la potestad punitiva. Desde este punto de vista, suele afirmarse que al establecer tipos penales debería hacerse prevalecer el uso de elementos descriptivos por sobre otras eventuales posibilidades técnico-legislativas. El artículo se ocupa de desmitificar esta afirmación, a propósito de algunos ejemplos extraídos de la regulación legal de los delitos de burto y robo con fuerza en las cosas.
\end{abstract}

PRINCIPIO DE LEGALIDAD - HURTO - ROBO CON FUERZA

\section{Descriptive elements as a legislative technique: critical considerations towards the crimes of theft and breaking and entering}

\section{Abstract}

The legislative technique used in the writing of a criminal regulation must be extremely cautious to obtain the proposed objectives and to respect the limits imposed to legal punitive authority. From this point of view, it is usually stated that the use of descriptive concepts should prevail over other technical-legal devices when a crime is defined. This article demystifies this affirmation, due to some examples extracted from the legal regulation of the crimes of theft and breaking and entering.

\section{LEGALITY PRINCIPLE - THEFT-BREAKING AND ENTERING}

* Trabajo redactado en el marco del proyecto de investigación Fondecyt N N $^{0} 070421$, "Formulación de una teoría general de los delitos contra el patrimonio con base en el derecho chileno: estudio dogmático y crítico", dirigido por Guillermo Oliver Calderón, en la Pontificia Universidad Católica de Valparaíso.

** Abogada, Doctora en Derecho, Profesora de Derecho Penal, Pontificia Universidad Católica de Valparaíso, Chile. magdalenaossandon@yahoo.es. Artículo recibido el 29 de diciembre de 2008 y aceptado para su publicación por el Comité Editorial el 18 de mayo de 2009. 


\section{IMPORTANCIA DE LA TÉCNICA LEGISLATIVA EN EL DERECHO PENAL}

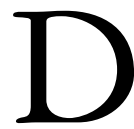
etrás de cada norma penal existe una decisión jurídica, decisión de incriminar ciertas conductas que afectan bienes jurídicos estimados merecedores y necesitados de protección. Es esa decisión la que se concreta en la configuración de una norma de conducta, es decir, en un mandato o una prohibición. No hay norma sin decisión. A partir de ella se genera el Derecho, por lo que constituye el elemento dinámico y central del mismo, ${ }^{1}$ y permite percibir el significado de las normas e instituciones jurídicas, en cuanto éstas representan el resultado de esa decisión.

La norma de conducta que expresa la decisión jurídica adoptada tiene que ser plasmada en un texto a través de la redacción de una disposición legal concreta. La redacción de ese texto jurídico pretende aprehender el fenómeno jurídico singular que ha sido objeto de esa decisión, esto es, expresarlo u objetivarlo en términos lingüísticos de un modo que no puede ser más que aproximativo. La expresión legislativa constituye, por tanto, una interpretación de la decisión jurídica, ${ }^{2}$ su concreción lingüística. ${ }^{3}$

La evidente dificultad que plantea la redacción de todo precepto legal se acentúa en el ámbito del Derecho penal. Por una parte, es problemático dar a los supuestos de la vida -materia sobre la que recae el Derecho- una expresión conceptual en la norma. Asunto en que, además, hay que recordar que "el acto legislativo no describe, sino que valora y, por consiguiente, no crea configuraciones de acción puramente neutrales, sino, ante todo, tipos de injusto". ${ }^{4}$

Por otra parte, en el interior de cada precepto se manifiesta la compleja tensión entre la finalidad de protección de bienes jurídico-penales que persigue el Derecho penal, por un lado, y el aseguramiento de garantías para el infractor, por otro, dado que la intervención penal constituye una reacción punitiva formalizada. La formulación concreta de la disposición debe esforzarse por respetar los principios que rigen en Derecho penal; grosso modo, debe satisfacer las exigencias del principio de ofensividad y, al mismo tiempo, conseguir la máxima determinación en la descripción de las conductas prohibidas, en atención al principio de legalidad. ${ }^{5}$

1 "El Derecho se crea a golpe de decisión", afirma expresivamente Robles, G., El Derecho como texto (Cuatro estudios de Teoría comunicacional del Derecho), Madrid, Civitas, 1998, p. 17. Sobre la teoría de la decisión jurídica vid. ibídem, pp. 99-104, y Schäffer, "Racionalización y creación del Derecho" (trad. Montoro Chiner), en Documentación Administrativa 218-219, 1989, p. 155.

${ }^{2}$ En este sentido, Hruschka, J., La comprensione dei testi giuridici (trad. Scuola di perfezionamento in diritto civile dell’Università di Camerino a cura di Pietro Perlingieri), Camerino, 1983, p. 23.

${ }^{3}$ Resulta así que el procedimiento legislativo contiene una estructura semejante a la del proceso de aplicación del Derecho, cfr. Kaufmann, A., "Concepción hermenéutica del método jurídico" (trad. Zafra Valverde), en Persona y Derecho n 35, 1996, pp. 20-23, el mismo, Filosofía del Derecho (trad. Villar Borda/ Montoya), Bogotá, Univ. Externado de Colombia, 1999, pp. 54-56, 169-196, 248-249.

${ }^{4}$ Vives Antón, Fundamentos del sistema penal, Valencia, Tirant lo Blanch, 1996, p. 268, con referencia a Mezger, Tratado de Derecho penal, I (trad. Rodríguez Muñoz), Madrid, 1955, pp. 378-379.

${ }^{5}$ Desde un punto de vista garantístico, los principios de ofensividad y legalidad no tienen que estar en contradicción, sino que deben conjugarse y compenetrarse, de modo que el delito se configure, precisamente, como un becho ofensivo típico, en expresión de Mantovani, F., "Il principio di offensività nello schema 
En ese proceso de creación del Derecho, el legislador cuenta con diversas opciones e instrumentos para plasmar la decisión jurídica. Cada una de estas posibilidades puede tener consecuencias disímiles, por ejemplo, en relación con el principio de legalidad -cuyo cumplimiento depende, en gran medida y en primer lugar, de la forma concreta que adopte la descripción típica-, ${ }^{6}$ con la finalidad que persigue la norma, su integración en el sistema normativo al que pertenece, etc.

En consecuencia, la forma que asume una disposición jurídica no es una cuestión secundaria, sino que puede tener gran relevancia práctica. Afecta al contenido de la norma, porque es en la redacción concreta de una disposición normativa donde se recoge, delimita y consolida, en cierta medida, ese contenido, ${ }^{7}$ especialmente en el ámbito penal, en el que el respeto por las formas es una característica esencial. ${ }^{8}$

De la redacción de las normas y la correcta elaboración de los textos normativos se ocupa la técnica legislativa, como parte de la teoría de la legislación. ${ }^{9}$ El estudio de la técnica legislativa abarca cuestiones de lenguaje y homologación formal, materias procedimentales y aspectos más de fondo, como la lógica interna de las normas, su sistematización externa, el análisis previo de su operatividad, costes y repercusiones, etc., todo lo cual incide en la forma que se adopte al redactar la disposición legal. Es decir, de acuerdo con un concepto amplio de técnica legislativa, ${ }^{10}$ la calidad de las normas "depende

di delega legislativa per un nuovo Codice Penale”, en RIDPP 1997, pp. 315-316. El principio de ofensividad, aunque relacionado con la finalidad de protección del Derecho penal, también debe entenderse como límite. Ferrajoli, L., Derecho y razón. Teoría del garantismo penal, Madrid, Trotta, 1995, p. 467, afirma que "la necesaria lesividad del resultado (...) condiciona toda justificación utilitarista del Derecho penal como instrumento de tutela y constituye su principal límite axiológico externo”.

6 "La eficacia práctica del principio de legalidad depende en gran medida de cuestiones de técnica legislativa, que abarcan tanto aspectos de enunciado lingüístico como aspectos de estructura normativa", Doval Pais, Posibilidades y límites para la formulación de las normas penales. El caso de las leyes en blanco, Valencia, Tirant lo Blanch, 1999, p. 25.

${ }^{7}$ Más aún, la forma es parte del contenido, en tanto en cuanto constituye su apariencia visible: "Die Form gehört zum Inhalt, sie ist 'der Inhalt von seiner Sichtbarkeit'”, afirma Tiedemann, K., Tatbestandsfunktionen im Nebenstrafrecht, Tübingen, 1969, p. 73 (destacado en el original).

${ }^{8}$ Así, por ejemplo, Silva Sánchez, Aproximación al Derecho penal contemporáneo, Barcelona, Bosch, 1992, pp. 250 y ss. destaca que la característica que singulariza al Derecho penal como medio de control social no radica en lo punitivo, sino en lo jurídico y, en concreto, en el alto grado de formalización que esto supone.

${ }^{9}$ En este sentido la definen Atienza, M., Contribución a una teoría de la legislación, Madrid, Civitas, 1997 , p. 55; Iturralde Sesma, "Cuestiones de técnica legislativa”, en RVAP n 24, 1989, p. 225 y Ruiz Sanz, M., "De la ciencia de la legislación hacia la técnica legislativa", en AFD XIV, 1997, p. 644. Se distinguiría de la teoría de la legislación porque esta última no tiene finalidad práctica, al menos a corto plazo, sino que surge de la necesidad de encontrar una explicación del fenómeno de crisis de la legislación, en tanto que la técnica legislativa, de la necesidad de dar una respuesta a dicha crisis. Aunque no se puede desconocer que todos los estudios sobre legislación tienen una innegable vocación práctica.

${ }^{10}$ Wróblewski, "Propos final", en AAVV, La Science de la Législation, Paris, Presses Universitaires de France, 1988, pp. 106-107, distingue dos enfoques o modos de tratar los problemas dentro de la teoría de la legislación: uno minimalista, exclusivamente técnico, que trata de los medios o instrumentos dirigidos a optimizar la legislación y lograr los objetivos propuestos desde el punto de vista socio-técnico, esto es, de sus cualidades instrumentales, sin plantear los fines o los valores a los que se orienta la legislación; en otras palabras, un enfoque que elude las cuestiones relativas a la ética y política legislativa (cfr. Marcilla Córdoba, 
no sólo de sus propiedades internas sino, sobre todo, de su idoneidad para alcanzar sus objetivos, integrados en el ordenamiento jurídico". ${ }^{11}$ La optimización en la redacción de las normas que pretende la técnica legislativa no se reduce a un análisis exclusivamente técnico-formal, sino que ha de considerar la materia a regular, el contenido específico de la norma, el cumplimiento de sus fines, el respeto de los valores que la informan y, en términos generales, el contenido político propio de toda decisión legislativa. ${ }^{12}$

Aunque teóricamente es posible diferenciar entre componentes políticos y técnicos del proceso de creación de las normas jurídicas, ${ }^{13}$ en la práctica ambos se fusionan, pues lo material y lo formal resultan aspectos inseparables al momento de adoptar una decisión normativa. Los problemas sobre el momento y las circunstancias en que se deben formular las normas, la ponderación de los intereses en juego y, en general, la determinación de los fines concretos que se persiguen con la formulación de una disposición jurídica constituyen el ámbito propio de la decisión política. Pero todas estas cuestiones impregnan también la dimensión técnica e influyen en la fórmula concreta que se adopte en la redacción de cada precepto. La forma de las leyes está condicionada tanto por la materia a que se refieren como por el sistema político en que se insertan, por lo que los estudios de técnica legislativa pueden y deben conectarse con el contenido de la norma y con el fundamento político que rige la actividad estatal.

Tanto así, que es posible afirmar que existe un especial vínculo entre los Estados democráticos y el interés por una mayor racionalidad legislativa, ${ }^{14}$ la que puede

G., "Sobre la necesidad de una nueva ciencia de la legislación”, en Carbonell/Pedroza de la Llave (coords.), Elementos de técnica legislativa, México, 2000, p. 108). El enfoque maximalista, en tanto, considera el valor de los objetivos que persigue la legislación y condiciona la elección de los medios técnicos en función de esos valores.

${ }^{11}$ Sainz Moreno/da Silva Ochoa, "Propuesta de directrices para mejorar la calidad de las leyes", en Sainz Moreno/da Silva Ochoa (coords.), La calidad de las leyes, Vitoria, Parlamento Vasco, 1989, p. 391.

${ }^{12}$ No es posible aislar los problemas del lenguaje y de la técnica de las leyes de la consideración de todo el contexto institucional en el cual se desarrolla el proceso de formación de la ley, cfr. Cervati, "Metodi e tecnica della legislazione in alcuni recenti orientamenti della dottrina di lengua tedesca", en Il Foro italiano CVIII, 1985, pp. 281-282.

${ }^{13}$ Vid., por ejemplo, Bulygin, E., "Teoría y técnica de la legislación”, en Alchourrón/Bulygin, Análisis lógico y Derecho, Madrid, Centro de Estudios Constitucionales, 1991, pp. 411-412.

${ }^{14}$ Vínculo que ha sido señalado por numerosos autores, vid., por todos, García Amado, J. A., "Razón práctica y teoría de la legislación”, en Derechos y libertades n ${ }^{\circ}$ 9, 2000, pp. 313-314, con referencias a Noll, Öhlinger, Schäffer, Badura y Schreckenberger. Ello se debe a que la optimización en la producción de normas significa buscar mayores dosis de racionalidad en la actividad legislativa y en sus resultados, y en el marco de un Estado social y democrático de Derecho la búsqueda de una mayor racionalidad en la legislación, que va más allá de la que concede la legitimidad democrática, constituye una exigencia propia del sistema. "La efectividad del principio democrático exige algo más que la pura articulación formal de ciertos órganos depositarios de la representación; supone, en lo que a la legislación se refiere, la plasmación práctica y procedimental de una cierta racionalidad que tiene su eje en el respeto de los interlocutores y de su igualdad y en el procedimiento que asegura todo ello y la trasparencia del resultado". García Amado, Derechos y libertades $\mathrm{n}^{\circ}$ 9, 2000, p. 314. La democracia no puede considerarse sólo como un modo de designación del poder, sino que constituye también un modo de ejercicio del mismo, Rivero, "À propos des métamorphoses de l'Administration d'aujourd'hui: démocratie et administration”, en AAVV, Mélanges offerts à René Savatier, Paris, 1965, p. 821, cit. por Martín Rebollo, "La técnica legislativa: reflexiones discretas sobre el método 
considerarse incluso como una exigencia constitucional, cuyo incumplimiento implica una violación del principio de seguridad jurídica. ${ }^{15}$

En definitiva, la redacción de cada precepto debe responder a una racionalidad específica, que por más técnica que sea no puede desatender su sustrato valorativo que nutre y desarrolla cada una de las decisiones legislativas concretas.

De lo expuesto, puede concluirse la importancia de la técnica legislativa, cuyo objetivo es la optimización en la redacción del texto normativo. Y, al mismo tiempo, la necesidad de integrar las consideraciones formales con las que se refieren al contenido material de la norma, pues es innegable que la forma de una disposición jurídica no resulta absolutamente independiente de su contenido. La forma no existe por sí sola, sino en función de la norma que contiene.

Ello conduce a que puedan plantearse consideraciones técnico-legislativas de diversa índole según el sector del ordenamiento jurídico de que se trate, y aun dentro de un sector como el penal, que se justifique el estudio particular de un grupo específico de delitos. Porque la discusión sobre técnica legislativa para la configuración de los tipos penales debe empaparse de las consideraciones de dogmática jurídica y política criminal. ${ }^{16}$ Esta clase de examen es el que se realiza en lo que sigue, en que se revisará, en particular, el empleo de elementos descriptivos en los delitos que protegen la propiedad, específicamente en el ejemplo de los delitos de hurto y robo con fuerza, para enjuiciar su capacidad e idoneidad como instrumento para la configuración de los tipos penales.

\section{LOS ELEMENTOS DESCRIPTIVOS}

Tradicionalmente los elementos descriptivos se conciben como aquellos términos que extraen su significado directamente de la realidad de la experiencia sensible, es decir, que reproducen determinados datos o procesos corporales o anímicos y que son verificados de

y el procedimiento", en Corona Ferrero/Pau Vall/Tudela Aranda (coords.), La técnica legislativa a debate, Madrid, Tecnos, 1994, p. 74.

Ubica esta exigencia de racionalidad dentro del discurso postmoderno y como imperativo elemental de la forma republicana de gobierno, que se proyecta con especial intensidad en el ejercicio del poder punitivo, Arocena, G., "La racionalidad de la actividad legislativa penal como mecanismo de contención del poder punitivo estatal", en Política Criminal No 6, 2008. A1-6, pp. 2-4. [http://www.politicacriminal. cl/n_06/a_1_6.pdf]

${ }^{15}$ En este sentido, en España, Sainz Moreno, F., "La técnica normativa: visión unitaria de una materia plural”, en Corona Ferrero/Pau Vall/Tudela Aranda (coords.), La técnica legislativa a debate, Madrid, Tecnos, 1994 , p. 20 y Tudela Aranda, "La legitimación competencial de las leyes y la técnica normativa”, en Corona Ferrero/Pau Vall/Tudela Aranda (coords.), La técnica legislativa a debate, Madrid, Tecnos, 1994, p. 88. En Alemania también se ha postulado la existencia de un supuesto deber constitucional de legislar bien, cfr. Hoffmann, "Das verfassungsrechtliche Gebot der Rationalität im Gesetzgebungsverfahren”, en ZG 1990, pp. 109 y ss.

${ }^{16}$ Línea metodológica como la que en su momento trazó Roxin, al integrar la dogmática jurídica con la política criminal. Vid. Roxin, C., Política Criminal y Sistema del Derecho penal (trad. Muñoz Conde), Barcelona, Bosch, 1972, passim. 
modo cognoscitivo por el juez. ${ }^{17}$ En otras palabras, términos que contienen descripciones asequibles a la percepción sensorial y que no requieren de un juicio valorativo para su conocimiento y comprensión. Se conocen por mera observación. ${ }^{18}$

Sin embargo, algunos autores prefieren sustituir los criterios de lo fáctico y lo sensible por parámetros que caracterizarían mejor a este grupo de elementos, describiéndolos, por ejemplo, como términos cuyo contenido y significado se obtiene por medio de conceptos que proporciona la experiencia y el propio significado gramatical de los términos, ${ }^{19} \mathrm{o}$, en forma más simple, como aquéllos que utilizan palabras del lenguaje común. ${ }^{20}$

De todos modos, la idea es que estos elementos no requieren de un especial proceso intelectivo y valorativo para su comprensión. En esta línea, es posible reconocer todavía otro intento de definición, que en este caso opera por exclusión: los términos descriptivos son aquellos comprensibles sin necesidad de remitirse a algún-cualquier-género de normas. Ello puede ocurrir porque a través de él se enuncia directamente una realidad sensorial, o porque las palabras por las que se expresa pertenecen al lenguaje normal y no pretenden ofrecer una significación diferente de aquella que se deduzca de su lectura, ${ }^{21}$ o porque son parte del saber empírico y lógico de los hombres y han sido previamente incorporados,

${ }^{17}$ De este modo la expone, como la posición tradicional, Roxin, C., Derecho Penal. PG I (trad. Luzón Peña/Díaz y García Conlledo/De Vicente Remesal), Madrid, Civitas, 1997, §10/58, p. 306.

18 Caracteriza esta posición como uno de los polos sobre los que gira la distinción entre elementos descriptivos y normativos, Díaz y García Conlledo, M., "Los elementos normativos del tipo penal y la teoría del error", en Estudios jurídicos en memoria del profesor Dr. D. José Ramón Casabó Ruiz, I, Universitat de Valencia, 1997 , p. 660, n. 12. En España ha sido, con matices, la concepción mayoritaria, vgr. Bacigalupo Zapater, E., Principios de Derecho penal. Parte general, $5^{a}$ ed., Madrid, Akal, 1998, p. 234; Berdugo Gómez de la Torre/ Arroyo Zapatero/García Rivas/Ferré Olive/ Serrano Piedecasas, Lecciones de Derecho penal. PG, 2a ed., Barcelona, Praxis, 1999, p. 157; Bustos Ramírez, Manual de Derecho penal. PG, Barcelona, PPU, 1994, p. 270; Cerezo Mir, Curso de Derecho penal español. PG, II, Teoría jurídica del delito, 6a ed., Madrid, Tecnos, 1998, p. 117; Cuello Contreras, El Derecho penal español, curso de iniciación. PG, $2^{\text {a }}$ ed., Madrid, Civitas, 1996; del Rosal, Tratado de Derecho Penal Español, I, $3^{\mathrm{a}}$ ed., Madrid, Villena, 1978, p. 781; Mir Puig, Derecho penal. PG, $7^{\mathrm{a}}$ ed., Montevideo-Buenos Aires, BdeF, 2005, L 9/67; Polaino Navarrete, Derecho penal. PG, I, Barcelona, Bosch, 1996, p. 410; Rodríguez Devesa/Serrano Gómez, Derecho Penal español. PG, $18^{a}$ ed., Madrid, Dykinson, 1995 , p. 416 y Rodríguez Mourullo, Derecho penal. PG, Madrid, Civitas, 1978, p. 253.

También en Chile, se ubican en esta línea la definición Náquira Riveros, Derecho penal. Teoría del delito, I, McGraw-Hill, Santiago, 1998, p. 70 e, indirectamente, Politoff/Matus/Ramírez, Lecciones de Derecho penal chileno, Parte general, $2^{\mathrm{a}}$ ed., Santiago, Edit. Jurídica de Chile, 2008, p. 184.

${ }^{19}$ Cfr. Morales Prats, en Quintero Olivares (drg.), Manual de Derecho Penal. PG, Pamplona, Aranzadi, 1999, p. 60. Bustos Ramírez, "El tratamiento del error en la reforma de 1983: artículo 6 bis a)", en ADPCP 1985 , p. 707, estima que para su conocimiento basta con una aprehensión sensorial y, según el caso, una menor o mayor adecuación con una significación lingüística general. Cobo del Rosal/Vives Antón, Derecho penal. PG, $5^{\text {a }}$ ed., Valencia, Tirant lo Blanch, 1999, p. 331, aluden a que en su interpretación se ha de recurrir a la experiencia externa o interna del sujeto. Palazzo, Il Principio di determinatezza nel Diritto penale, Padova, CEDAM, 1979, p. 334, califica como descriptivos tanto los elementos naturalísticos (los que pertenecen al puro estrato naturalístico del ser), como aquellos que deben su subsistencia objetiva y real al estado actual de la civilización y de la cultura. En el mismo sentido, Padovani, Diritto penale, $5^{\mathrm{a}}$ ed., Milano, Giuffrè, 1999 , p. 138.

${ }^{20}$ Vid. Landecho Velasco/Molina Blázquez, Derecho penal español. PG, 5 a ed., Madrid, Tecnos, 1996, p. 251.

${ }^{21}$ Cfr. Quintero Olivares, Manual, p. 309. 
de un modo más o menos uniforme, en el mundo de conocimientos y experiencias de los sujetos de una determinada comunidad. ${ }^{22}$ Todas estas no son más que causas que determinan lo esencial, lo característico, que consiste en que en los términos descriptivos no es necesario referirse a alguna norma para precisar su significado y contenido. ${ }^{23}$

En todo caso, cualquiera sea la definición que se adopte, con frecuencia se sostiene que resulta más conveniente recurrir a esta clase de elementos en la descripción de las conductas típicas. ${ }^{24}$

Esto se debe, fundamentalmente, a que la descriptividad de las estructuras lingüísticas empleadas en la formulación del tipo penal permite transmitir un mensaje de modo claro, directo y concreto en relación con las conductas específicamente prohibidas. El sentido de la norma queda radicado en límites materiales, fácticos, y la relación comunicativa con los destinatarios es mejor en la medida en que el lenguaje usado conserve su significación ordinaria.

Además, si se consigue una mayor determinación y una configuración cerrada de los tipos, los elementos descriptivos permitirán una mejor delimitación de la gravedad de las conductas proscritas. De este modo, se acomodan mejor las bases para un juicio de proporcionalidad y se restringe el espacio de libertad del juez en la concreción del mismo, favoreciendo un trato igualitario de los diversos supuestos sometidos a su decisión. En definitiva, por ser más precisos, ofrecerían una mayor seguridad jurídica.

En el fondo, esto no ha de sorprender, pues si el tipo contiene la descripción del hecho voluntario al cual se asociará una pena, resulta lógico que el legislador se sirva preferentemente de ellos. ${ }^{25}$

Sin embargo, la capacidad e idoneidad de los elementos descriptivos para la redacción de los tipos penales, por sobre la de otras técnicas legislativas, puede cuestionarse por varias razones. El punto de partida para estas consideraciones es una cuestión de fondo: la idea de que el tipo penal no consiste en una mera descripción de una conducta, sino que implica algo más.

${ }^{22}$ Cfr. Luzón Peña, Curso de Derecho penal. PG, I, Madrid, Universitas, 1996, p. 351, caracteriza los elementos descriptivos como "aquellos para cuyo conocimiento y comprensión basta con el común saber empírico y lógico de los hombres sobre sí mismos y sobre las realidades y fenómenos del mundo exterior, sin necesidad de recurrir a normas para comprender su significado”. En el mismo sentido, Díaz y García Conlledo, en Estudios Jurídicos, p. 662.

${ }^{23}$ En este sentido Cury, E., Derecho penal. Parte general, $8^{a}$ ed., Santiago, Universidad Católica de Chile, 2005 , p. 280, los concibe como aquellos conceptos que se refieren a algo cuya presencia es aprehensible mediante una pura operación cognoscitiva, sin necesidad de efectuar una valoración. De acuerdo, Bullemore/ Mackinnon, Curso de Derecho penal, II, Santiago, LexisNexis, 2005, p. 29.

${ }^{24}$ Opinión generalizada; vid., a título ejemplar, la sentencia del Tribunal Constitucional español 127/1990, FD 3. ${ }^{\circ}$ b); Ferrajoli, Derecho y razón, pp. 120 y ss., Náquira Riveros, Derecho penal, I, p. 71 y Morales Prats, F., "Omnis definitio in iure periculosa? El problema de las definiciones en el Código penal español y en el Proyecto de Código penal de 1992”, en Cadoppi (coord.), Omnis definitio in iure periculosa? Il problema delle definizioni legali nel Diritto penale, Padova, CEDAM, 1996, p. 317. Lo cuestionan, entre otros, Bustos Ramírez, Manual de Derecho Penal. PG, p. 365; Doval Pais, Posibilidades y límites, p. 69 y Madrid Conesa, La legalidad del delito, Valencia, Universidad, 1982, p. 121.

${ }^{25}$ Parafraseando a Cury, Derecho penal. PG, p. 280. 


\section{PREMisa: EL USO PRESCRIPTIVO DEL LENGUAJE LEGAL}

En el lenguaje legal en que se forman y expresan las normas, el uso que se hace de las palabras será, en general, un uso directivo o prescriptivo. ${ }^{26}$ Las palabras utilizadas en un enunciado legal no se limitan a describir o constatar una realidad, o a transmitir información, como sucede en el discurso asertivo, sino que tienen un sentido realizativo, un alcance directivo, por medio del cual se pretende organizar u orientar la realidad en una determinada dirección. Esto se consigue a través de la prescripción, prohibición o permisión de ciertas conductas, ${ }^{27}$ dentro de una efectiva relación comunicativa con sus destinatarios. ${ }^{28}$ Esto es lo que da sentido a las expresiones utilizadas en la ley, por lo que debe ser el eje central de su interpretación. ${ }^{29}$ En otras palabras, en la labor hermenéutica del Derecho, y particularmente del Derecho penal, no se puede olvidar que se está ante un uso prescriptivo del lenguaje, que persigue motivar o dirigir a sus destinatarios e imputarles las conductas contrarias a lo preceptuado. Las palabras que contiene la ley están teñidas por esta función y no pueden desvincularse de ella. ${ }^{30}$

También si se niega la naturaleza imperativa de las normas jurídico-penales y se consideran sólo como normas de valoración, igual habrá que convenir en que el lenguaje

${ }^{26}$ Recordando, al respecto, la afirmación de Bulygin, E., "Normas, proposiciones normativas y enunciados jurídicos" en Alchourrón/Bulygin, Análisis lógico y Derecho, Centro de Estudios Constitucionales, Madrid, 1991, p. 174: "las normas son el resultado de cierto uso, a saber, el uso prescriptivo del lenguaje". Se trata, por ende, de una concepción expresiva de las normas.

${ }^{27}$ Sobre el significado de la regla como exigencia orientativa de la acción, que excluye un carácter descriptivo, explicativo o predictivo, vid. Robles, G., Las reglas del Derecho y las reglas de los juegos: ensayo de teoría analítica del derecho, Palma de Mallorca, Universidad, 1984, pp. 101-117.

${ }^{28}$ El mandato, orden o norma sólo resulta completo cuando se establece esta relación comunicativa. Sólo entonces puede afirmarse que existe un verdadero directivo de conducta, cuyo incumplimiento podrá ser imputado al sujeto. En cambio, no es posible desobedecer una orden o norma que no ha sido recibida por el destinatario o que no esté capacitado para cumplir o desobedecer. Por consiguiente, antes de que se establezca esa comunicación sólo puede existir un intento de directivo. En este sentido Wright, G. H. von, Norma y acción: una investigación lógica (trad. García Ferrero), Madrid, Tecnos, 1970, p. 129 y ss, 139; tesis que desarrolla coherentemente Molina Fernández, F., Antijuricidad penal y sistema del delito, Barcelona, Bosch, 2001, pp. 508 y ss., poniendo especial énfasis en el carácter comunicativo de las expresiones directivas y lo esencial que resulta la perspectiva del destinatario. Esto implica que la norma se entiende sólo en su dimensión particular, como obligación para un individuo concreto en una situación concreta, mientras que la formulación general o abstracta no hace sino inclusión de un número indeterminado de normas individuales y concretas. Antes de que exista el individuo obligado en la situación particular, la norma -entendida en sentido estricto- no existe. Ella puede haberse promulgado, tener vigencia y, desde este punto de vista, gozar de un nivel de existencia. De hecho, la doctrina jurídica suele considerar que la norma existe una vez que ha sido promulgada. Pero entendida así, en abstracto, no puede ser cumplida ni infringida y no se puede decir entonces que imponga algún tipo de comportamiento a alguien. Su existencia como expresión lingüística no es suficiente para que exista una norma imperativa, motivadora.

${ }^{29}$ Lo subraya especialmente Robles, El Derecho como texto, pp. 55-58.

${ }^{30}$ Esto conecta con la visión de la interpretación como un círculo hermenéutico: el significado de las palabras en cada caso concreto sólo puede inferirse de la conexión de sentido en el texto, y este a su vez, definitivamente, sólo del significado pertinente de las palabras que lo forman y de su combinación. Cfr. Larenz, K., Metodología de la Ciencia del Derecho (trad. Rodríguez Molinero), Barcelona, Ariel, 1994, pp. 194-195. 
legal no tiene una función meramente descriptiva, sino que debe plasmar una decisión previa que es esencialmente valorativa. ${ }^{31}$

Las consideraciones sobre el lenguaje conducen, por tanto, a la necesidad de que la interpretación de las normas esté orientada teleológicamente, porque el significado prescriptivo de las expresiones utilizadas en la ley está esencialmente vinculado al fin que la misma norma persigue. ${ }^{32}$ Siempre que se prescribe algo se hace en atención a un propósito determinado, y ese propósito queda, de alguna manera, objetivamente incorporado en la formulación de la norma. Y si la interpretación de las palabras de la ley debe quedar delimitada por su sentido literal posible, este sentido literal debe, a su vez, enmarcarse en los límites del uso prescriptivo de las expresiones y del fin de la prescripción.

En consecuencia, las palabras que emplea la ley han de entenderse en un sentido adscriptivo más que descriptivo, pues ellas se utilizan en función de una atribución de responsabilidad $^{33}$. De este modo, el uso prescriptivo del lenguaje implica una restricción de las posibilidades de interpretación, porque mientras en el ámbito del lenguaje ordinario el sentido adscriptivo es sólo uno de los que admite la expresión, dentro del lenguaje legislativo penal, y mientras el término sea usado en la descripción de una conducta típica, ésta es la única posibilidad de interpretación.

\section{LAS LIMITACIONES DE LOS ELEMENTOS DESCRIPTIVOS COMO TÉCNICA LEGISLATIVA}

La idea de que los elementos descriptivos constituyen una técnica legislativa que facilita la comunicación de la norma a sus destinatarios, y que favorece mayores cotas de proporcionalidad, igualdad y, muy especialmente, de certeza y seguridad jurídica, debe morigerarse por varias razones:

${ }^{31}$ En la descripción de la acción típica está implícito un juicio de valor, que debe coincidir en lo posible con el juicio valorativo, previo y abstracto, que motivó la creación de la figura. Siempre que el legislador promulga una ley se deja guiar por cierta intención reguladora y por consideraciones de justicia y de oportunidad, a las que subyacen valoraciones. Cfr. Larenz, Metodología, p. 203.

32 En este sentido Schünemann, B., "Introducción al razonamiento sistemático en Derecho penal”, en Schünemann (comp.), El sistema moderno del Derecho penal: cuestiones fundamentales (introducción, traducción y notas de Silva Sánchez), Madrid, Tecnos, 1991, p. 71.

33 Por lo demás, la interpretación propuesta no resulta ajena al significado del término en el lenguaje ordinario o corriente, sino que se apoya en su correlación con el uso general que el idioma permite. Precisamente, la filosofía analítica ha observado que los términos relativos a acciones no practican una descripción, sino más bien una adscripción, esto es, la atribución de responsabilidad moral por un hecho, cfr. Silva Sánchez, El delito de omisión: concepto y sistema, $2^{\mathrm{a}}$ ed., Buenos Aires, BdeF, 2003, p. 460.

Sobre el giro que supone el tomar conciencia de que lo decisivo no es la simple causación (naturalismo, plano fáctico), sino la imputación (normativismo, plano valorativo), vid. Sánchez-Vera Gómez-Trelles, J., Intervención omisiva, posición de garante y probibición de sobrevaloración del aporte, Bogotá, Universidad Externado de Colombia, 1995, pp. 56-57. 
a) Los elementos descriptivos siempre están provistos de un matiz valorativo, porque dentro de la ley penal todos los elementos son, cuanto más, cuasidescriptivos, ${ }^{34}$ y deben concretarse dentro del sentido de una prescripción jurídica.

b) En algunos casos el carácter descriptivo del tipo puede ser más aparente que real, cuando los elementos utilizados carecen de una correlación objetiva en la realidad del mundo exterior, es decir, cuando la descriptividad conseguida en el plano lingüístico no corresponde con realidades sociales bien delimitadas. ${ }^{35}$

c) El máximo inconveniente que presenta esta clase de técnica legislativa radica en la escasa capacidad de los términos fácticos para plasmar la decisión valorativa previa. En el fondo, la desnormativización o concreción de los criterios valorativos que subyacen a la decisión incriminatoria que se verifica al emplear términos descriptivos, implica aceptar limitaciones externas del sistema.

Por una parte, el empleo del lenguaje ordinario en la descripción típica condiciona las aspiraciones intrasistémicas del ordenamiento jurídico penal, pues el principio funcional de atribución que le es propio puede verse limitado por el sentido ordinario del lenguaje. Esta limitación opera, al menos, en el núcleo conceptual de los términos empleados, que configura caracterizaciones inequívocas de los estados de cosas a considerar. En lo que excede a dicho núcleo, el lenguaje ordinario permite la apertura del sistema tanto a consideraciones político-criminales como a valoraciones específicamente penales. ${ }^{36}$

También, desde este punto de vista, la mayor capacidad descriptiva de los elementos utilizados en la ley penal significa un límite ontológico a las necesidades conceptuales del sistema penal.

Todo esto comporta que utilizar términos descriptivos en la formulación típica supondrá siempre el riesgo de una tipificación excesiva o insuficiente en relación con el juicio valorativo abstracto que corresponde a la decisión incriminatoria. La limitada extensión que normalmente poseen, esto es, su reducida capacidad para abarcar conductas diversas, implica una reducción del perímetro de lo prohibido

${ }^{34}$ En la terminología de Wróblewski, cit. por Iturralde Sesma, V., Lenguaje legal y sistema jurídico, Madrid, Tecnos, 1989, p. 48. Es decir, aunque existe una descripción prima facie, su estructura profunda revela un carácter valorativo.

${ }^{35}$ Cfr. Fiandaca/Musco, Diritto penale. Parte generale, $4^{\mathrm{a}}$ ed., Bologna, Zanichelli, 2001, p. 72. Es lo que sucedió con el art. 603 del Código penal italiano - una modalidad del delito de plagio o secuestro- en el que se requería la concurrencia de una relación de dependencia psicológica entre dos sujetos. El artículo fue declarado inconstitucional por la Corte Costituzionale al comprobar la imposibilidad de asegurar de modo irrefutable el fenómeno requerido por la norma incriminadora (sentencia 96/1981, c.d. 2, en RIDPP, 1981, pp. 1147-1166).

${ }^{36}$ Cfr. Schünemann, en El sistema moderno, pp. 36 y 73. Reconoce que "la indeterminación del lenguaje ordinario (...) que comúnmente se ha interpretado como un inconveniente desde la perspectiva jurídica, podía, de ese modo, ser aprovechada a fin de garantizar la necesaria apertura del sistema, mientras que, por otro lado, los elementos del sistema precisados en sentido jurídico se cuidaban de la ordenación y canalización de los puntos de vista valorativos admitidos y del mantenimiento de un conocimiento jurídico asentado”. 
-de lo normativizado-, ${ }^{37}$ que puede dejar fuera del precepto penal conductas lesivas para el bien jurídico que se pretende proteger. Y a la inversa, aunque ha de ser un defecto menos frecuente, también puede parecer que se han incorporado algunos comportamientos que no se pretendía sancionar (equivocación por exceso). Ambas situaciones conducen a realizar correcciones interpretativas, a fin de evitar una aplicación absurda y no deseada del tipo. Pero una reinterpretación teleológica que pretenda corregir tales incoherencias -si fuese compatible con el principio de legalidad-podría llegar a deformar el texto legal, forzando el lenguaje legal de tal modo que resulte inútil en su función comunicativa ${ }^{38}$ y sobrepasando la certeza que inicialmente ofrecían los elementos de carácter descriptivo.

Al mismo tiempo, esa limitada capacidad de expresión ante la riqueza y variabilidad de la realidad puede conducir a la vulneración práctica del principio de igualdad, desde dos puntos de vista. Por una parte, porque esta limitación significa, en la práctica, la imposibilidad de considerar algunas circunstancias particulares de la situación concreta que se enjuicia y que la diferencian de otras. Y por otra, porque al dejar fuera del ámbito típico hechos que expresan un mismo desvalor, favorece la desigualdad en el tratamiento jurídico de situaciones que debieron tratarse del mismo modo.

d) Para evitar que ciertas situaciones desvaloradas queden fuera del ámbito típico sin dejar de utilizar elementos descriptivos, sería necesario multiplicar excesivamente los preceptos, lo que contradice el principio de economía legislativa y dificultaría, a su vez, las posibilidades de conocer las normas. Ello daría lugar a Códigos penales impracticables por su extensión, ${ }^{39}$ que pondrían en peligro la seguridad jurídica por la farragosidad del texto. ${ }^{40}$ En definitiva, una tipificación realizada a través de la formulación directa, detallada, concreta y casuística de todas las modalidades que integran la correspondiente figura, aunque parece deseable según las exigencias de claridad y precisión, resulta irrealizable en la práctica moderna. ${ }^{41}$

En esta dirección, para lograr una tipificación completa, se puede recurrir a enumeraciones casuísticas. Sin embargo, hay que reconocer que con ellas tampoco se puede lograr la plenitud, dado que el legislador nunca será capaz de enumerar todas las po-

${ }^{37}$ La formulación típica implica una concreción o desnormativización de las decisiones del legislador, cfr. Schünemann, en El sistema moderno, pp. 73-74. Si la traducción de dichas decisiones a estados descriptibles en términos empíricos opera ya en el nivel de la ley abstracta, el injusto jurídico-penal puede quedar reducido muy por debajo de su valoración de referencia.

38 Cfr. Vives Antón, en Cobo del Rosal (drg.), Comentarios al Código Penal, I, Madrid, Edersa, 1999, p. 507, n. 61 . Este aspecto coincide con una de las críticas que, desde una perspectiva metodológica, ha recibido la moderna dogmática teleológico-funcionalista, vid., por todos, Silva Sánchez, Aproximación, p. 71.

${ }^{39}$ Cfr. Doval Pais, Posibilidades y límites, pp. 50-51.

${ }^{40}$ En este sentido, Vidales Rodríguez, C., La eficacia retroactiva de los cambios jurisprudenciales, Valencia, Tirant lo Blanch, 2001, p. 45.

41 Doval Pais, Posibilidades y límites, p. 50, con ejemplos de antiguos textos de estilo casuístico, y Morales Prats, en Omnis definitio, pp. 317 y 322. También lo reconoce el Tribunal constitucional español en relación, por ejemplo, con el delito ambiental (STC 127/1990). 
sibilidades fácticas de conductas y sus diversas formas de aparición. Ante esta realidad se podría imponer una interpretación forzada para evitar lagunas de punibilidad, o bien se favorecerá la inclusión de cláusulas genéricas o analógicas -cuando se quiere solucionar el problema a nivel legislativo-, para completar la enumeración.

Por lo demás, el exceso casuístico trae consigo otros efectos negativos para la seguridad jurídica. En efecto, una descripción que fragmenta el precepto en una serie de hipótesis corre el riesgo de hacer indescifrable el sentido de la norma y, en consecuencia, compromete la función de orientación social que a ésta corresponde. ${ }^{42}$ Eventualmente, además, una tal factura casuística obstaculizaría la articulación con otras normas del sector jurídico, provocando una falta de armonización del conjunto normativo que se traduciría en dificultades para advertir los defectos lógicos del sistema -las contradicciones entre las normas- provocando casos de incerteza. ${ }^{43}$

e) Ni siquiera está libre de reparos una descripción legal demasiado precisa y definida obtenida gracias a un adecuado uso de elementos descriptivos, pues corre el riesgo de quedar obsoleta en poco tiempo, particularmente en los sectores de impronta técnica o económica. Como una mayor descriptividad es menos adaptable a las variaciones que pudiera sufrir la (des)valoración que fundamenta y justifica la norma, hace más difícil conocerla, y la necesidad de su modificación reiterada vuelve a constituirse en fuente de inseguridad.

f) Por último, en comparación con los elementos normativos, la idea de que los elementos descriptivos garantizan la taxatividad mejor que aquéllos, parte del supuesto de asociar lo normativo con lo valorativo y con la incorporación de un sentido abierto en el tipo, cuestión que no siempre es así. ${ }^{44}$

En definitiva, por tanto, las diversas exigencias que se imponen al formular un tipo penal y, especialmente, el respeto por el principio de determinación, pueden verse quebrantados tanto por elementos descriptivos como normativos. ${ }^{45}$ Es necesario atender al supuesto típico completo para juzgar su idoneidad en la descripción típica.

\section{El EJEMPLO DE LOS DELITOS DE HURTO Y ROBO CON FUERZA}

Entre los delitos contra la propiedad, tal como están tipificados en nuestra legislación, se aprecia una significativa tendencia a emplear elementos descriptivos. El resultado,

${ }^{42}$ Cfr. Mantovani, F., Diritto Penale, $3^{\mathrm{a}}$ ed., Padova, CEDAM, 1992, p. 101 y Padovani, Diritto penale, p. 36.

43 Doval Pais, Posibilidades y límites, p. 52, n. 76.

${ }^{44}$ Cfr. Doval Pais, Posibilidades y límites, pp. 65-66. Por lo mismo, tampoco es correcta la identificación de elemento normativo e indeterminación.

45 Por todos, Bustos Ramírez, Manual de Derecho penal. PG, p. 270; Cobo del Rosal/Vives Antón, Derecho penal. PG, p. 336 y Jakobs, G., Derecho penal. Parte general (trad. Cuello Contreras/Serrano González de Murillo), Madrid, M. Pons, 1995, §4/29, p. 97. 
sin embargo, está lejos de constituir una regulación adecuada, pues en su seno podemos encontrar muestras de casi todos los defectos recién descritos.

Así, por ejemplo, en la definición de los delitos de hurto y robo, cuando la ley habla de apropiarse de una "cosa", este término se interpreta unánimemente como referido a cosas corporales, que posean extensión, pues han de ser objetos susceptibles de aprehensión. ${ }^{46}$ En otras palabras, no se le asigna un sentido meramente descriptivo -pues, desde esta perspectiva, cosa podría equivaler a todo lo que tiene entidad, sea corporal o espiritual, natural o artificial, real o abstracta- ${ }^{47}$ sino que se lo concibe en función de la prohibición que se expresa en la norma, esto es, la de sustraer y apropiarse de lo ajeno.

Paradójicamente, esta restricción funcional del término cosa hace difícil incluir la sustracción de energía eléctrica, por citar un caso entre muchos, en el ámbito de aplicación del delito de hurto. Para sancionarlo ha sido necesario elaborar normas específicas (el actual art. 215 de la Ley General de Servicios Eléctricos, D.F.L. 4/2007 Ministerio de Economía, Fomento y Reconstrucción), pese a que la situación de hecho es desvalorada de modo similar a los supuestos tradicionales de hurto.

Por otra parte, la exigua capacidad denotativa de los términos fácticos usados en estas figuras obliga a correcciones interpretativas recurrentes, y generalmente lleva a transformar expresiones aparentemente descriptivas asignándoles un significado valorativo. Tal es el caso del "lugar destinado a la habitación" a que se refiere el art. 440 CP. Aunque su naturaleza es discutible, si el ideal técnico-legislativo es el uso de elementos descriptivos y esta mención legal puede entenderse en relación directa con la experiencia sensible, no se ve porqué habría que interpretarla de otro modo. Entonces, en la medida en que se la conciba como mera descripción de una realidad, estaría aludiendo a un espacio físico al que alguien ha asignado como finalidad la de servirle de lugar para alojarse. Si el lugar es físicamente habitable, bastaría con que alguna persona le hubiere dado como destinación servirle de morada en cualquier momento, para caracterizarlo como asignado a esa finalidad.

Sin embargo, mayoritariamente la doctrina asigna un alcance más limitado a esta expresión, en atención al bien jurídico protegido y a la relación sistemática con los demás preceptos que se refieren al robo con fuerza. Entonces, sólo se considera "lugar destinado a la habitación" aquél "cuya finalidad normal es servir de morada, aunque en el momento de perpetrarse el delito no esté habitado"; ${ }^{48}$ o aquel que sirve de vivienda pero en que las personas que en él viven están accidental, temporal o circunstancialmente ausentes. ${ }^{49}$ La Corte Suprema ha afirmado derechamente que "la distinción entre el lugar

${ }^{46}$ Por todos, Etcheberry, A., Derecho penal. Parte especial, III, Santiago, Edit. Jurídica de Chile, 1998, p. 299 y Politoff/Matus/Ramírez, Lecciones de Derecho penal chileno, Parte especial, 2a ed., Santiago, Edit. Jurídica de Chile, 2007, p. 302.

${ }^{47}$ Según la primera acepción de cosa contenida en el Diccionario de la Real Academia Española.

${ }^{48}$ Labatut Glena/Zenteno Vargas, Derecho penal, II, $7^{\text {a }}$ ed., Santiago, Edit. Jurídica de Chile, 2007, p. 207 (el destacado es nuestro). De acuerdo Politoff/Matus/Ramírez, Lecciones de Derecho penal chileno. PE, p. 336.

${ }^{49}$ Etcheberry, Derecho penal, III, p. 320 y Garrido Montt, M., Derecho Penal, IV, $3^{\text {a }}$ ed., Santiago, Edit. Jurídica de Chile, 2005, p. 223. 
destinado a la habitación y el no habitado tiene que efectuarse sobre una base valorativa, pues requiere evaluar hasta qué punto cabe temer, en las distintas clases de sitios, las posibilidades de un encuentro entre el hechor y terceros cuya vida o integridad corporal está sujeta al peligro de un ataque por parte de aquél".50,51

Es sabido, también, que la regulación legal de los delitos contra la propiedad se caracteriza por tipificaciones farragosas y un excesivo casuismo, especialmente en el caso de los delitos de robo con fuerza en las cosas, que ha sido objeto de reiteradas críticas por nuestra doctrina. ${ }^{52}$ Pese al esfuerzo del legislador por agotar las hipótesis, es imposible que una enumeración casuística cubra todas las posibilidades fácticas que quedan abarcadas por una decisión normativa.

En el delito de robo en lugar habitado, para seguir con el ejemplo, es necesario que la fuerza se exprese en alguna de las situaciones específicas enumeradas en el art. 440 CP. Pero fácilmente se descubren casos que quedan fuera de la descripción legal, pese a que involucran una misma afectación de los bienes jurídicos en juego y que demuestran también una especial potencia y determinación criminal en la conducta del autor. Por lo mismo, es frecuente encontrar argumentaciones y esfuerzos interpretativos para incluirlos en el tipo, no sin forzar el contenido descriptivo de los términos legales, o incluso, interpretándolos directamente como elementos normativos para ampliar su ámbito de aplicación. Así, por ejemplo, en principio parecen quedar fuera del sentido descriptivo de los términos legales los casos en que el autor entra por una vía normal y una vez dentro fractura puertas interiores, armarios, etc. ${ }^{53}$ si en lugar de fracturar

${ }^{50}$ Vid. SSCS Rol 2220-00 de 21 de agosto de 2000; Rol 1460-01, de 13 de junio de 2001; y Rol 1522-01 de 19 de julio de 2001 (el destacado es nuestro). En consecuencia, para decidir cómo calificar una casa de veraneo, nuestro máximo tribunal exige una evaluación caso a caso de la época del año, cercanía y facilidades para trasladarse a ella, acceso de personas encargadas de la mantención o seguridad del lugar, etc., factores de los que depende el mayor riesgo de un encuentro del delincuente con otra persona, que se vería en peligro. En los lugares no habitados dicho riesgo no resulta del todo exluido, pero es más remoto.

Por lo mismo, no deberían incluirse entre los lugares destinados a la habitación -pese a que naturalmente lo son-los inmuebles recién construidos que todavía no se encontraran ocupados por sus moradores o los departamentos pilotos que sirven para promocionar la venta de un edificio en construcción, toda vez que ambos se encuentran destinados a la habitación futura pero no actual de personas. En este sentido, la sentencia de la Corte de Apelaciones de San Miguel, Rol 2322-90, de 28 de octubre de 1991.

${ }^{51}$ Un análisis crítico de esta jurisprudencia en De la Fuente Hulaud, "Delitos contra bienes instrumentales”, en Revista de Derecho de la Universidad Adolfo Ibáñez, N 2, 2005, Peñalolén y Viña del Mar, pp. 564-565, quien interpreta la expresión "lugar habitado o destinado a la habitación" conforme al uso normal del lenguaje, y concluye que "un lugar es habitado en razón de su función, es decir, en razón de su destino actual” (el destacado es nuestro). Por lo tanto, la fórmula legal es analítica o explicativa, referida a una sola clase de lugar, pues no hay lugares habitados que no estén a la vez destinados a la habitación ni lugares destinados a la habitación (actual) que no estén habitados.

52 Mera, J., Hurto y robo, Santiago, ConoSur, 1995, p. 89 y ss.; Künsemüller Loebenfelder, C., "Delitos de hurto y robo: una reforma inaplazable en el Código penal chileno", en Figueiredo Dias/Serrano Gómez/ Politoff Lifschitz/Zaffaroni (dir.), El penalista liberal. Homenaje a Manuel de Rivacoba y Rivacoba, Hammurabi, Buenos Aires, 2004, p. 459 y Garrido Montt, M., Derecho Penal, IV, p. 217.

53 Crítico, Etcheberry, Derecho penal, III, p. 324. 
una puerta para ingresar, la desprende de las bisagras $;{ }^{54}$ si utiliza una llave extraviada o indebidamente retenida; si emplea una tarjeta magnética o un control remoto (sean falsos, sustraídos, extraviados, retenidos, etc.) $;{ }^{55}$ si fractura un picaporte, tranca, cerrojo, etc. ${ }^{56}$ Todas éstas son situaciones que representan un empleo de energía física especial para acceder a la cosa superando los sistemas de defensa o custodia en que se encuentra, por lo que merecerían ser calificados como robo con fuerza, pese a lo cual no quedan

${ }^{54}$ Sin embargo, Garrido Montt, M., Derecho Penal, IV, p. 227, estima que fracturar implica romper o sacar, violentamente o por medios más diestros, como desatornillar o liberar de sus soportes (?). También, Politoff/Matus/Ramírez, Lecciones de Derecho penal chileno, PE, p. 342, concluyen que el desprendimiento de la puerta constituye su fractura (?), fundamentalmente, para evitar la paradoja de sancionar esa hipótesis con menor pena que la de quien remueve una ventana o retira sólo el vidrio de ésta y entra por ahí, hipótesis naturalmente reconducibles al supuesto de "entrar por vía no destinada al efecto", pues en todos esos casos la conducta es similar.

55 Aunque pronunciada en relación con un robo en lugar no habitado, la argumentación empleada por la Corte Suprema para estimar que una tarjeta equivale a una llave es aplicable aquí: "la tarjeta substraída (...) permitía la entrada al lugar de comisión del delito a la vez que posibilitaba el acceso al dinero de la cuenta correspondiente, de modo que equivale a una llave toda vez que accionó el mecanismo de la cerradura, sea de la puerta del recinto sea del mueble en cuyo interior se guardaba el dinero (previa información de la clave) y para lo cual estaba diseñada específicamente, de suerte que era el complemento de esas cerraduras, esto es, se trataba de una llave verdadera que había sido substraída como se dejó establecido en el fallo". SCS Rol 3606-00, de 8 de marzo de 2001 (considerando 5 ${ }^{\circ}$ ). La propia sentencia, eso sí, agrega que la tarjeta cumple la función de un instrumento semejante a una ganzúa, de accionar el mecanismo de la cerradura, por lo que también podría incluirse en la cláusula de apertura con que termina la enumeración de las circunstancias típicas. Pero para estos efectos interesa destacar la interpretación que se hace del término llave.

De acuerdo, Dorn, C., "Clonación de instrumentos privados mercantiles", en Revista de Derecho, CDE, $\mathrm{N}^{\circ}$ 7, 2002, p. 50, habla de la necesidad de "reformular el concepto de llave, el cual debe entenderse en un sentido funcional y no en uno literal o semántico". Frente a la problemática a la que se enfrenta (la de sustracción de dinero de un cajero automático), este autor entiende que incluso la expresión abrir ha de interpretarse en un sentido que va más allá de la noción semántica o gramatical, "para que la modalidad de fuerza descrita se configure deberá entender la acción de apertura del mueble cerrado desde un punto de vista funcional, ya que la utilización de la tarjeta falsa permitirá acceder al sistema regulador de las transacciones y operaciones que a través del cajero pueden efectuarse y, además, desde ese instante el sujeto posee el dominio de las acciones que se llevarán a cabo a fin de obtener el dinero contenido en el interior de la máquina”.

También acepta la comprensión de tarjetas con banda magnética u otras similares como llaves, justificable en cuanto "lo esencial del concepto radica en su carácter de complemento de una cerradura que permite abrirla del modo normal, siendo indiferentes las características técnicas de una y otra", Hernández Basualto, H., "Uso indebido de tarjetas falsificadas o sustraídas y de sus claves", en Política Criminal $\mathrm{N}^{\circ} 5$ (2008), A2-5, p. 11. [http:www.politicacriminal.cl/n_05/a_2_5.pdf]. Sin embargo, cuestiona que pueda configurar un robo con fuerza en las cosas la sustracción de dinero de un cajero automático con tarjeta falsa, porque no se configuran los demás requisitos que suponen las diversas modalidades de esta clase de ilícitos (pp. 11-13).

${ }^{56}$ Etcheberry, Derecho penal, III, p. 326, entiende que como estos mecanismos tienen "el mismo carácter defensivo de una pared", se configura la circunstancia descrita en el art. $440 \mathrm{~N}^{\circ} 2$. Pero es evidente que, en un sentido natural, el término pared no incluye en su ámbito de extensión a los cerrojos, barras, picaportes, etc. Tampoco podría afirmarse que estos mecanismos constituyen cerraduras. Y una interpretación semánticodescriptiva impide, a su vez, incluir estos casos entre las hipótesis de ingreso por vía no destinada al efecto cuando se trata del picaporte o barra que asegura una puerta, ni en las de rompimiento o fractura de una puerta, en la medida en que ésta resulte intacta tras la maniobra. 
comprendidos en la norma si los términos en ella usados se interpretan de un modo meramente descriptivo.

En otros supuestos, como el del robo en bienes nacionales de uso público o en sitios no destinados a la habitación (art. $443 \mathrm{CP}$ ), en la enumeración de las formas de fuerza específicamente sancionadas se incluye la utilización de medios de tracción, caso que no representa necesariamente la superación de ningún sistema de resguardo. Dentro de la enumeración de casos que contiene la norma, la introducción de una hipótesis diferente a las anteriores oscurece su sentido, pues no queda claro si eso no constituye más que un exceso del legislador, o si la decisión de proteger la propiedad en sitios menos custodiados quiere ser más intensa por la misma razón.

Otro de los defectos en que puede incurrir la tipificación excesivamente descriptiva es la pronta obsolescencia. En algunos supuestos de hurto agravado ello es palmario. Así, el conocido como famulato impropio del art. $447 \mathrm{~N}^{\circ} 2$, se refiere al "obrero, oficial o aprendiz", que comete el delito en una “casa, taller o almacén”. Todos estos términos, aunque no son completamente descriptivos $-\mathrm{y}$ ya hemos visto que ninguna palabra, dentro de la ley, tiene ese carácter-, pueden interpretarse en su sentido natural y ordinario, restringiéndose, por tanto, a la clase de trabajadores que se indican y en los lugares específicos a que se refiere la disposición. Aunque esto pudo ser adecuado al momento de dictación del Código penal, en la actualidad implicaría una discriminación respecto de otros trabajadores dependientes, que también pueden incurrir en el delito abusando de la posición en que se encuentran. Por lo mismo, algunos autores proponen realizar una interpretación progresiva, es decir, una interpretación que considere el progreso científico y cultural que se ha experimentado entre la fecha en que se dicta la ley y aquella en que se la interpreta, de conformidad con la idea de que la interpretación ha de buscar el querer actual de la norma. Según esto, las expresiones legales deben entenderse como referidas a los trabajadores dependientes, ${ }^{57}$ por hechos cometidos en toda clase de establecimientos comerciales o industriales. ${ }^{58}$ Sin embargo, no les falta razón a quienes acusan que ello implica, simplemente, incorporar por analogía ciertos casos que no están dentro en el sentido literal posible. ${ }^{59}$

${ }^{57}$ En contra, Etcheberry, Derecho penal, III, p. 310 deja fuera a los empleados.

${ }^{58}$ Es el sentido que le asignan algunas sentencias, por ejemplo, de la CA. de Valparaíso, Rol 28.813-00 de 16 de mayo de 2002 (incluye en el $447 \mathrm{~N}^{\circ} 2$ a los guardias de seguridad de un supermercado), o de la CA de San Miguel, Rol 3.236-98 de 6 de diciembre de 2002 (aunque referido al $446 \mathrm{~N}^{\circ} 1$, en el que incluye a las cajeras de un establecimiento comercial, lo que implica interpretar que ese lugar constituye una casa). Con todo, estas resoluciones no resultan tan objetables en la medida en que aunque consideraron que el supuesto de hecho era subsumible en los diversos numerales del art. 447, no hicieron uso de la facultad de agravar la pena que confiere dicha norma.

Etcheberry, Derecho penal, III, p. 310 hace una interpretación amplia del lugar, pero restrictiva en cuanto a las personas y entiende que la disposición no es aplicable a los empleados.

59 Por eso Garrido Montt, Derecho Penal, IV, p. 172, considera que el precepto es, por regla general, improcedente. 


\section{LA ALTERNATIVA: LOS ELEMENTOS NORMATIVOS}

Tal como no se puede identificar la descriptividad con una mayor seguridad, tampoco puede decirse lo contrario, esto es, que los elementos normativos o valorativos impliquen necesariamente inseguridad. ${ }^{60}$ La supuesta vinculación entre término normativo e indeterminación deriva de un concepto restringido de este género de elementos, un concepto en el que se incluye sólo a aquellos términos necesitados de complementación valorativa. Sin embargo, el criterio valorativo se suele interpretar de un modo más amplio, que admite hacer ulteriores distinciones. En el aspecto que ahora interesa, ya Erik Wolf ${ }^{61}$ propuso la clasificación que distingue entre elementos llenos de valor (wertgefüllter) o rellenables de valor (wertausfüllbarer) por una parte, y elementos necesitados de una integración valorativa (wertausfüllungs-bedürftiger) por otra. En otras palabras, tanto hay elementos normativos que dejan al aplicador del Derecho un margen de valoración especialmente amplio -en cuyo caso sí existirá un problema de determinación-, como otros en los que el juicio de valor está integrado en la norma a que el término se remite. ${ }^{62}$ Por lo tanto, en este ámbito el análisis requiere distinguir diversas clases de elementos normativos.

Pero al enjuiciarlos, si consideramos que lo fundamental es plasmar la decisión valorativa que subyace a la norma, es fácil advertir que ello puede conseguirse mejor con una mayor normativización en la redacción de los tipos.

Sin pretender agotar el tema, bastará sólo con referirnos a algunos de los elementos normativos que parecen más conflictivos. Por ejemplo, los términos elásticos, cláusulas generales o conceptos jurídicos indeterminados. El empleo de estos términos con elasticidad y capacidad de síntesis aparece como más idóneo para obtener una certeza (casuística) potencial, preferible a la imposible certeza de una casuística absoluta, siempre y cuando se remitan a principios valorativos o pautas extralegales objetivas y convencionales, sin quedar sometidos al mero arbitrio judicial, pues entonces podrían satisfacer adecuadamente las exigencias de seguridad jurídica. ${ }^{63}$ Más todavía, las cláusulas generales permiten una aplicación del Derecho ligada a principios superiores de justicia material,

${ }^{60}$ Aunque esa es una opinión generalizada. Más aún, se ha llegado a afirmar que ellos implican siempre un cierto grado de subjetivismo (Muñoz Conde/García Arán, Derecho penal. Parte general, $4^{\mathrm{a}}$ ed., Valencia, Tirant lo Blanch, 2000 p. 291) o que el tribunal adopta ante ellos una "actitud valorativa o emocional" (Del Rosal, Tratado de Derecho Penal Español, p. 781, y similar Polaino Navarrete, Derecho penal. PG, I, p. 410). En definitiva, son considerados un riesgo para la seguridad jurídica, por lo que sería aconsejable, al construir el tipo penal, evitarlos o restringirlos en la mayor medida posible.

${ }^{61}$ Wolf, E. Die Typen der Tatbestandsmässigkeit, Breslau, 1931, p. 58, cit. por Madrid Conesa, La legalidad del delito, p. 187.

62 "No hay un declive de determinación desde los elementos descriptivos del delito (...) descendiendo hacia los normativos, ya que los elementos normativos están determinados si la valoración relevante está a su vez determinada", Jakobs, Derecho penal. PG, \$4/29, p. 97.

${ }^{63}$ En este sentido, el TC español ha reiterado que el empleo de conceptos jurídicos indeterminados no vulnera la exigencia de lex certa -como garantía de certidumbre y seguridad jurídica-, siempre que su concreción sea razonablemente factible en virtud de criterios lógicos, técnicos o de experiencia que permitan prever, con suficiente seguridad, la conducta regulada; vid., por ejemplo, SSTC 62/1982; 122/1987, FD 3. ${ }^{\circ}$ y 150/1991, FD 5.․ En Alemania la opinión extendida es que las cláusulas generales que mencionan valora- 
conciliándolo con la estabilidad normativa y su no fosilización. ${ }^{64}$ Naucke ha destacado cómo la imprecisión propia de esta clase de elementos ha sido generalmente interpretada por la jurisprudencia a favor del reo. ${ }^{65}$ De esta forma, la inseguridad que podría emanar de expresiones poco claras o determinadas se traduce en una ampliación del espacio de libertad frente a las pretensiones punitivas del Estado, sin contravenir el fundamento garantístico sobre el que se apoya la exigencia de seguridad.

Es obvio que la posibilidad de emplear elementos valorativos en la descripción típica se enfrenta a varias objeciones. En primer lugar, porque dejan una puerta abierta para que, en algún momento, deje de aplicarse la norma en ese sentido favorable; en el intertanto, la mera posibilidad de que eso suceda disminuiría la confianza de que puede gozar el ciudadano. Por otra parte, las posibilidades de conocimiento de la materia de prohibición se alejan del alcance del ciudadano, en la medida en que ésta no emana exclusivamente de la descripción penal. Pero, además, cuando la remisión se efectúa a normas sociales o culturales, la pluriculturalidad de la realidad social actual hace que cada vez sean menos los asuntos en que puede afirmarse la existencia de un consenso generalizado que dote de un contenido pacífico e indiscutible a estos elementos normativos extrajurídicos. ${ }^{66} \mathrm{Su}$ indeterminación sólo puede paliarse relativamente a través de una interpretación progresiva que atienda a la evolución social, ${ }^{67}$ pero que resta estabilidad y seguridad al Derecho.

Pero, insistimos, el juicio ha de hacerse caso a caso. Y si el fundamento del principio de legalidad -más que asegurar la previsibilidad de la reacción estatal, la posibilidad del conocimiento de las prohibiciones penales, la seguridad jurídica o legitimidad democrática- es ofrecer una garantía para evitar la arbitrariedad judicial, ${ }^{68}$ los elementos

ciones extrajurídicas sólo se podrían complementar mediante valoraciones indiscutidas, cfr. Jakobs, Derecho penal. $P G, \$ 4 / 32$, p. 99, con abundante bibliografía.

${ }^{64}$ Cfr. Naucke, W., Über Generalklauseln und Rechtsanwendung im Strafrecht, Tübingen, J.C.B. Mohr, 1973 , pp. 15-16.

${ }^{65}$ Naucke, Über Generalklauseln, passim. En el mismo sentido Palazzo, F., "Certezza del diritto e codificazione penale”, en Politica del Diritto, n 3, 1993, p. 369, destaca el rol garantista asumido por la jurisprudencia.

${ }^{66}$ Por eso Neumann, Franz, El Estado democrático y el Estado autoritario, Buenos Aires, 1968, pp. 36-37 (cit. por Vives Antón, T., "Dos problemas del positivismo jurídico", en La libertad como pretexto, Valencia, Tirant lo Blanch, 1995, p. 154), considera que estos elementos carecen de contenido específico. El propio Larenz, Metodología, p. 284, indica que esa difícil determinación del contenido social de un elemento conduce a que éste pase a medirse según las pautas fundamentales de valor del orden jurídico, especialmente de la Constitución, y por las pautas directivas establecidas por la propia jurisprudencia. Pero no parece que esas pautas de valor sean tan claras ni lo suficientemente estables como para solucionar el problema de la seguridad jurídica

${ }^{67}$ Morales Prats, en Omnis definitio, p. 323.

${ }^{68}$ Cfr. Jakobs, Derecho penal. PG, \$4/9, p. 82 y Madrid Conesa, La legalidad del delito, p. 29. No podemos compartir la arraigada y generalizada opinión que asigna al principio de legalidad la misión de hacer previsible la reacción penal, entre muchas razones, porque esa previsibilidad es prácticamente imposible, porque en la realidad los sujetos poco conocen las normas, porque el problema del conocimiento de las normas radica en la culpabilidad y sólo se refiere al injusto, no a la punibilidad, etc. En profundidad, Madrid Conesa, $L a$ legalidad del delito, pp. 14-17. Por lo demás, el propio concepto de previsibilidad ha ido evolucionando en 
normativos que gocen de una base objetiva de decisión pueden resultar una técnica especialmente adecuada.

En relación con este grupo de elementos, cabe hacer mención especial de los elementos cuantitativos, como "grave perjuicio", “concreto peligro", "especial, gravedad", etc., cuyo uso es cada vez mayor en la legislación penal. Ellos pueden constituir una forma de paliar en algo los defectos de una forma de tipificación demasiado amplia, al requerir una especial gravedad de la conducta y de la lesión o puesta en peligro del bien jurídico-penal. ${ }^{69}$ Ciertamente son elementos que adolecen de una esencial imprecisión, que trasladan al juez parte de la decisión incriminatoria y de proporcionalidad. Por lo tanto, su admisibilidad va a depender, fundamentalmente, de si el resto de la descripción típica contiene un injusto suficientemente delineado, en que se manifieste la necesidad y merecimiento de pena, o, especialmente, si existen pautas objetivas para determinar esa gravedad. Si, por el contrario, es el elemento valorativo-cuantitativo el que concentra el desvalor de la figura típica, la inseguridad se haría intolerable.

Un método intermedio entre la casuística y las cláusulas generales es el recurso a ejemplos típicos, técnica que significa una mayor flexibilidad que se corresponde con una inseguridad jurídica aún soportable. ${ }^{70}$ Esta técnica consiste en que la descripción genérica, abstracta y valorativa del tipo o de uno de sus elementos, es complementada con ejemplos legislativos en que esa descripción típica se concreta.

Ahora bien, los supuestos en que el tipo contiene una ejemplificación explicativa de un género de hipótesis ya completamente definido en la ley no deben confundirse con aquellos que incluyen una lista o registro sustitutivo de la definición legislativa. Mientras la primera constituye una legítima técnica de normación sintética, en la segunda el género de las hipótesis reguladas en la ley quedaría incompletamente representado en el listado ejemplificativo, obligando a individualizar los supuestos típicos a través de un verdadero razonamiento analógico que resulta inconstitucional. Esto último es lo que generalmente sucede cuando se emplean expresiones como en casos similares o análogos, que no se puedan completar por aplicación de un criterio unívoco legislativamente pre-

un sentido objetivo, de cognoscibilidad de la ley; cfr. Tiedemann, Tatbestandsfunktionen, p. 185. Para Madrid Conesa, La legalidad del delito, p. 13, esta objetivación del concepto termina por dejar de lado la misma idea de previsibilidad, y se corresponde más bien con la de protección frente a la arbitrariedad.

Por último, resulta obvio que esa seguridad jurídica en sentido objetivo, que informa y fundamenta el principio de legalidad en todas sus manifestaciones, habrá de traducirse, como consecuencia, en una mayor seguridad subjetiva o confianza, o, cuando menos, en la ausencia de temor respecto de reacciones aflictivas del Estado que sean totalmente impredecibles.

69 Martínez-Buján Pérez, Derecho penal económico. Parte General, Valencia, Tirant lo Blanch, 1998, p. 141. En este sentido, por ejemplo, la Corte Costituzionale italiana, 15-16 maggio 1989, n. 247, c.d. 4, estima que gran parte de los conceptos elásticos que expresan una realidad cuantitativa o temporal a través de términos imprecisos, constituyen un intento del legislador por precisar y delimitar la esfera de operatividad de un tipo demasiado amplio o genérico.

${ }^{70}$ Cfr. Kaufmann, A., Filosofía del Derecho, pp. 169-170. 
fijado; entonces estas referencias se configurarían como cláusulas abiertas que extienden excesivamente el marco típico. ${ }^{71}$

En Alemania, los Regelbeispiele se utilizan con frecuencia para regular los supuestos de especial gravedad de un delito, mediante la introducción de un grupo de casos más concretamente perfilados que los demás. ${ }^{72}$ Estos casos no son considerados elementos cualificativos del tipo -elementos típicos- sino reglas de determinación judicial de la pena, de carácter no vinculante. Es decir, establecida una penalidad especial para supuestos graves, la concurrencia de los elementos de alguno de los ejemplos es sólo un indicio de la presencia de uno de esos casos especialmente graves. El juez, en consecuencia, puede negar ese efecto indiciario y la gravedad del hecho, a pesar de concurrir todos sus elementos y, en sentido contrario, admitir un caso como especialmente grave aunque no se cumplan los elementos de ningún ejemplo típico. ${ }^{73}$ El problema es que una vez reconocido el carácter no vinculante de estos ejemplos, se termina suprimiendo, en buena medida, lo que se había ganado en seguridad jurídica.

\section{Valoración del AnTeproyecto de Código Penal}

El Anteproyecto de Código penal mejora sustancialmente la regulación de los delitos contra la propiedad, simplificando las normas de modo radical. Para empezar, en lugar de varios tipos de hurtos, hurtos agravados, diversas modalidades de robo con fuerza en las cosas, robo por sorpresa y robo con violencia o intimidación, la ley se estructura sobre la base de sólo tres figuras: hurto, robo con fuerza en lugar habitado y robo con violencia o intimidación.

En relación con los aspectos que aquí nos interesan, el anteproyecto sustituye muchos de los excesos casuísticos de la actual normativa a través del empleo de elementos normativos como los descritos. Así, la diversa gravedad que puede ostentar un delito de hurto se recoge a través de algunas circunstancias que modifican la pena, sea para atenuarla o agravarla.

Un cambio fundamental es que en lugar de ordenar las penas según la cuantía de lo sustraído (un sistema de elementos descriptivos numéricos, que pese a la certeza que ofrece resulta demasiado rígido) se recurre a dos cláusulas valorativas cuantitativas: cuando las cosas son de infimo valor se puede aplicar sólo la sanción pecuniaria prescindiendo de la pena de reclusión, mientras que cuando el hecho revista especial gravedad, en atención al valor de la cosa apropiada o a los efectos especialmente perjudiciales que su pérdida tenga para la víctima, la pena se puede elevar en grado (art. 148 inc. $2^{\circ}$ ). La fórmula resulta adecuada, especialmente porque la propia ley determina parámetros objetivos para efectuar la medición.

${ }^{71}$ Cfr. Fiandaca/Musco, Diritto penale. PG, p. 96; Mantovani, Diritto penale, pp. 107-110.

72 Por ejemplo, los $\$ 94$ II, 125a, 243, 292 II, 302a II StGB.

${ }^{73}$ Cfr. Jescheck, H.-H., Tratado de Derecho penal. Parte general, I (trad. y adiciones Mir Puig/Muñoz Conde), Barcelona, Bosch, 1981, p. 367; Roxin, Derecho penal. PG, §10/133, p. 339. 
Por otra parte, también se agrava la pena del hurto en otros tres supuestos: a) cuando, tratándose de cosas que se encuentran en lugares cerrados o en sus dependencias, se haya ingresado mediante escalamiento, por vía no destinada al efecto, mediante forado, rompimiento de paredes, pisos o techos, fractura de puertas o ventanas o uso de llaves falsas, ganzúas u otros instrumentos semejantes; b) cuando se hubieran destruido, inutilizado o neutralizado los dispositivos de seguridad con que cuenta la cosa; c) cuando, tratándose de cosas que la víctima lleva consigo, se haya obrado por sorpresa, siempre que no se hubiera empleado violencia o intimidación.

Como se advierte, el Anteproyecto conservó en sus líneas fundamentales algunas de las fórmulas actualmente vigentes para indicar las modalidades que debe asumir la fuerza en un robo, pero ubicándolas como una forma agravada de hurto. Por lo mismo, damos aquí por reproducidas las consideraciones que formulamos en su momento. La tendencia comparada, en tanto, va en la línea de simplificar aún más estos supuestos. La legislación alemana, por ejemplo, parece sustentar un modelo parecido al del anteproyecto, pues contiene una enumeración de circunstancias similar; ${ }^{74}$ sin embargo, se diferencia radicalmente en la medida en que la enunciación de hipótesis que realiza la norma alemana no es taxativa, sino que estamos ante un caso de Regelbeispiele. En efecto, el encabezado advierte que "un caso especialmente grave se presenta por regla general cuando...", dejando abierta la posibilidad de incluir como casos graves algunos que, aunque no coincidan literalmente con la descripción, correspondan a los parámetros que se expresan a través de ella.

En realidad, en estos supuestos, lo que realmente interesa para sancionar el atentado contra la propiedad con una pena mayor que la que correspondería por la figura básica de hurto es una especial actitud del delincuente frente a los resguardos que el propietario ha dispuesto para proteger sus bienes. ${ }^{75}$ La ley enumera situaciones en que el autor realiza un enérgico despliegue de energía física, sea para burlar, destruir o anular las defensas que existen para proteger la propiedad. Ante tal constatación, no se ve por qué el legislador no pudo redactar las disposiciones aludiendo precisamente a eso, esto es, a cualquier ingreso que se verifique venciendo los obstáculos o defensas dispuestos para evitarlo. En su lugar, ha intentado describir los casos en que ello ocurre. Pero desde un punto de vista meramente fáctico o de inmediata conexión con la realidad sensible es imposible abarcar todas las situaciones.

En relación con el delito de robo en lugar habitado, el Anteproyecto exige también que el hecho se realice con alguna de las dos primeras circunstancias agravatorias del

${ }^{74} \mathrm{El} \S 243$ StGB considera ciertos casos especialmente graves como burtos calificados, entre los que destaca, para efectos de nuestro análisis, dos: a) si para la ejecución del hecho, cometa robo con fractura, escale, irrumpa con una llave falsa, o con otro dispositivo no destinado para la apertura regular en un edificio, un local de servicios o de negocios, o se mantenga clandestino en el sitio, y b) si hurta una cosa que esté especialmente asegurada contra robo por medio de un receptáculo cerrado u otra forma de protección.

75 Carrara, Programa § 2154, afirmaba que “...cuanto mayores son los obstáculos superados por el ladrón, tanto más decrece, respecto de su audacia, la potencia de la defensa privada”, “...el individuo ya no se encuentra en sus propios medios una tutela que valga para proteger su cosa, y el temor más intenso y difundido de la repetición exige de la defensa pública una energía más potente”, cit. por Etcheberry, Derecho penal, III, p. 316. 
hurto. Luego, vuelve a constreñirse injustificadamente el tipo. Y aquí la situación es más criticable, pues cuando se trata de un lugar habitado lo más relevante es la posibilidad de encuentro del autor con los moradores, el peligro para su vida o su integridad física (como pone de manifiesto el propio inciso final del art. 152 del Anteproyecto, que permite rebajar la pena cuando de las circunstancias concretas del hecho se desprenda que ese peligro no existió). Así, no se explica por qué emplear una técnica legislativa restrictiva, cuando se pudo prescindir, incluso, de exigir una modalidad especial de ingreso al lugar, ${ }^{76}$ o bien, describirla de un modo más amplio. ${ }^{77}$

Con todo, tanto el Anteproyecto como la actual regulación emplean una expresión a la que se puede dar un sentido normativo amplio, que ayude a salvar los problemas de un casuismo naturalista extremo. Así, cuando se habla de ingresar al lugar del robo por "vía no destinada al efecto" estamos ante una fórmula que podría llegar a considerarse, incluso, como una cláusula general. Ella se refiere, desde este punto de vista, a cualquier vía que no esté destinada "al efecto", es decir, al ingreso de terceros. ${ }^{78}$ En consecuencia, se incluirían aquí todos los supuestos descritos a continuación por las diversas disposiciones del Anteproyecto y del Código penal (escalamiento, forado, rompimiento de paredes, pisos o techos, fractura de puertas o ventanas o uso de llaves falsas, verdadera sustraída, ganzúas u otros instrumentos semejantes), así como todos aquellos casos que dudosamente quedaban incluidos en la enumeración legal, porque quien ingresa por el hueco de una puerta que previamente ha desmontado o destrabado, que ha abierto con una llave no autorizada por el propietario, con una tarjeta, control remoto, etc. Siempre que una puerta está cerrada y se abre por cualquier medio, se estaría ingresando por una vía no destinada al efecto. ${ }^{79}$

En definitiva, se ha pretendido demostrar mediante los ejemplos expuestos que el uso de elementos descriptivos no siempre constituye la técnica legislativa más recomendable para redactar los tipos penales. Dentro de ciertos límites -que se trate de una descripción completa, que existan pautas objetivas de valoración, etc-, puede ser aconsejable recurrir a términos normativos, pues permiten plasmar mejor una decisión que reviste, precisamente, ese carácter.

${ }^{76}$ La ley italiana, por ejemplo, agrava el hurto por el mero hecho de que el culpable, para cometer el hecho, se introduzca o se mantenga en un edificio u otro lugar destinado a la habitación (art. $625 \mathrm{~N}^{\circ} 1$ Codice penal)

${ }^{77} \mathrm{Al}$ estilo francés, en que el art. 311-4 Nº 6 del Code pènal habla de penetrar al lugar "con astucia, fractura o escalamiento".

${ }^{78}$ Conclusión a la que llega de la Fuente Hulaud, en Revista de Derecho de la Universidad Adolfo Ibáñez, $\mathrm{N}^{\circ}$ 2, p. 573, basándose en que lo esencial en el robo en lugar habitado es que se ingresa a la morada venciendo los obstáculos dispuestos para impedir el ingreso de terceros. Por ende, lo decisivo "no es tanto qué modalidad de quebrantamiento de las trabas puestas al ingreso se verifica, sino si fue necesaria la neutralización de esas defensas" (destacado en el original).

${ }^{79}$ Para un caso en que el autor del robo removió un vidrio trizado de una ventana, introdujo su mano, corrió pestillo y entró por la puerta, de la Fuente Hulaud, en Revista de Derecho de la Universidad Adolfo Ibáñez, $\mathrm{N}^{\circ} 2$, p. 573, entiende que se trató de un ingreso por vía no destinada "al efecto". 


\section{BIBLIOGRAFÍA}

Arocena, G., "La racionalidad de la actividad legislativa penal como mecanismo de contención del poder punitivo estatal", en Politica Criminal No 6, 2008, A1-6, pp. 1-15. [http://www. politicacriminal.cl/n_06/a_1_6.pdf]

Atienza, M., Contribución a una teoría de la legislación, Madrid, Civitas, 1997.

Bacigalupo Zapater, E., Principios de Derecho penal. Parte general, $5^{a}$ ed., Madrid, Akal, 1998.

Berdugo Gómez de la Torre/Arroyo Zapatero/García Rivas/Ferré Olive/ Serrano Piedecasas, Lecciones de Derecho penal. PG, $2^{\mathrm{a}}$ ed., Barcelona, Praxis, 1999.

Bulygin, E., "Normas, proposiciones normativas y enunciados jurídicos" en Alchourrón/ Bulygin, Análisis lógico y Derecho, Centro de Estudios Constitucionales, Madrid, 1991, pp. 169-193.

Bulygin, E., "Teoría y técnica de la legislación”, en Alchourrón/Bulygin, Análisis lógico y Derecho, Madrid, Centro de Estudios Constitucionales, 1991, pp. 409-425.

Bullemore/Mackinnon, Curso de Derecho penal, II, Santiago, LexisNexis, 2005.

Bustos Ramírez, "El tratamiento del error en la reforma de 1983: artículo 6 bis a)", en ADPCP 1985, pp. 703-719.

Bustos Ramírez, Manual de Derecho penal. PG, Barcelona, PPU, 1994.

Cerezo Mir, Curso de Derecho penal español. PG, II, Teoría jurídica del delito, $6^{a}$ ed., Madrid, Tecnos, 1998.

Cervati, "Metodi e tecnica della legislazione in alcuni recenti orientamenti della dottrina di lengua tedesca", en Il Foro italiano CVIII, 1985, pp. 280-287.

Cobo Del Rosal/Vives Antón, Derecho penal. PG, $5^{\text {a }}$ ed., Valencia, Tirant lo Blanch, 1999.

Cury, E., Derecho penal. Parte general, $8^{a}$ ed., Santiago, Universidad Católica de Chile, 2005.

De la Fuente Hulaud, "Delitos contra bienes instrumentales", en Revista de Derecho de la Universidad Adolfo Ibáñez, $\mathrm{N}^{\circ}$ 2, Peñalolén y Viña del Mar, 2005.

Del Rosal, Tratado de Derecho Penal Español, I, $3^{a}$ ed., Madrid, Villena, 1978.

Díaz y García Conlledo, M., "Los elementos normativos del tipo penal y la teoría del error", en Estudios jurídicos en memoria del profesor Dr. D. José Ramón Casabó Ruiz, I, Universitat de Valencia, 1997, pp. 657-703.

Dorn, C., "Clonación de instrumentos privados mercantiles", en Revista de Derecho, CDE, No 7 , 2002.

Doval Pais, Posibilidades y límites para la formulación de las normas penales. El caso de las leyes en blanco, Valencia, Tirant lo Blanch, 1999.

Etcheberry, A., Derecho penal. Parte especial, III, Santiago, Edit. Jurídica de Chile, 1998.

Ferrajoli, L., Derecho y razón. Teoría del garantismo penal, Madrid, Trotta, 1995.

Fiandaca/Musco, Diritto penale. Parte generale, $4^{\mathrm{a}}$ ed., Bologna, Zanichelli, 2001.

García Amado, J. A., "Razón práctica y teoría de la legislación", en Derechos y libertades no 9 , 2000, pp. 299-317.

Garrido Montt, M., Derecho Penal, IV, $3^{a}$ ed., Santiago, Edit. Jurídica de Chile, 2005.

Hernández Basualto, H., "Uso indebido de tarjetas falsificadas o sustraídas y de sus claves", en Política Criminal No 5, 2008, A2-5, pp. 1-38. [http:www.politicacriminal.cl/n_05/a_2_5.pdf]

Hoffmann, "Das verfassungsrechtliche Gebot der Rationalität im Gesetzgebungsverfahren", en Zeitschrift für Gesetzgebung 1990, pp. 109 y ss.

HruschKa, J., La comprensione dei testi giuridici (trad. Scuola di perfezionamento in diritto civile dell'Università di Camerino a cura di Pietro Perlingieri), Camerino, 1983.

Iturralde Sesma, "Cuestiones de técnica legislativa”, en Revista Vasca de Administración Pública $\mathrm{n}^{\mathrm{o}} 24,1989$, pp. 225-254. 
Iturralde Sesma, V., Lenguaje legal y sistema jurídico, Madrid, Tecnos, 1989.

Jakobs, G., Derecho penal. Parte general (trad. Cuello Contreras/Serrano González de Murillo), Madrid, M. Pons, 1995.

Jescheck, H.-H., Tratado de Derecho penal. Parte general, I (trad. y adiciones Mir Puig/Muñoz Conde), Barcelona, Bosch, 1981.

Kaufmann, Arthur, "Concepción hermenéutica del método jurídico" (trad. Zafra Valverde), en Persona y Derecho n ${ }^{\circ} 35,1996$, pp. 11-38.

Kaufmann, Arthur, Filosofía del Derecho (trad. Villar Borda/Montoya), Bogotá, Univ. Externado de Colombia, 1999.

KÜNSEMÜLler Loebenfelder, C., "Delitos de hurto y robo: una reforma inaplazable en el Código penal chileno", en Figueiredo Dias/Serrano Gómez/Politoff Lifschitz/Zaffaroni (dir.), El penalista liberal. Homenaje a Manuel de Rivacoba y Rivacoba, Hammurabi, Buenos Aires, 2004, pp. 457-479.

Labatut Glena/Zenteno Vargas, Derecho penal, II, $7^{\text {a }}$ ed., Santiago, Edit. Jurídica de Chile, 2007.

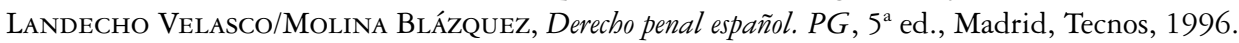

Larenz, K., Metodología de la Ciencia del Derecho (trad. Rodríguez Molinero), Barcelona, Ariel, 1994.

Luzón Peña, Curso de Derecho Penal. Parte general, I, Madrid, Universitas, 1996.

MAdrid Conesa, La legalidad del delito, Valencia, Universidad, 1982.

Mantovani, F. "Il principio di offensività nello schema di delega legislativa per un nuovo Codice Penale", en Rivista Italiana di Diritto e Procedura Penale 1997, pp. 313-337.

Mantovani, F., Diritto Penale, $3^{a}$ ed., Padova, CEDAM, 1992.

Marcilla Córdoba, G., "Sobre la necesidad de una nueva ciencia de la legislación", en Carbonell/Pedroza de la Llave (coords.), Elementos de técnica legislativa, México, 2000, pp. 93-115.

Martín Rebollo, "La técnica legislativa: reflexiones discretas sobre el método y el procedimiento", en Corona Ferrero/Pau Vall/Tudela Aranda (coords.), La técnica legislativa a debate, Madrid, Tecnos, 1994, pp. 73-82.

Martínez-Buján Pérez, Derecho penal económico. Parte General, Valencia, Tirant lo Blanch, 1998.

Mera, J., Hurto y robo, Santiago, ConoSur, 1995.

Mir Puig, Derecho penal. PG, $7^{\text {a }}$ ed., Montevideo-Buenos Aires, BdeF, 2005.

Molina Fernández, F., Antijuricidad penal y sistema del delito, Barcelona, Bosch, 2001.

Morales Prats, en Quintero Olivares (drg.), Manual de Derecho Penal. PG, Pamplona, Aranzadi, 1999.

Morales Prats, F., "Omnis definitio in iure periculosa? El problema de las definiciones en el Código penal español y en el Proyecto de Código penal de 1992”, en Cadoppi (coord.), Omnis definitio in iure periculosa? Il problema delle definizioni legali nel Diritto penale, Padova, CEDAM, 1996, pp. 275-331.

Muñoz Conde/García ArÁn, Derecho penal. Parte general, $4^{a}$ ed., Valencia, Tirant lo Blanch, 2000. NÁquira Riveros, Derecho penal. Teoría del delito, I, McGraw-Hill, Santiago, 1998.

NAUCKe, W., Über Generalklauseln und Rechtsanwendung im Strafrecht, Tübingen, J.C.B. Mohr, 1973.

Padovani, T., Diritto penale, $5^{\text {a }}$ ed., Milano, Giuffrè, 1999.

Palazzo, F., "Certezza del diritto e codificazione penale", en Politica del Diritto, $\mathrm{n}^{\circ}$ 3, 1993 , p. 369, destaca el rol garantista asumido por la jurisprudencia.

Palazzo, F., Il Principio di determinatezza nel Diritto penale, Padova, CEDAM, 1979.

Polaino Navarrete, M., Derecho penal. Parte general, I, Barcelona, Bosch, 1996.

Politoff/Matus/Ramírez, Lecciones de Derecho penal chileno, Parte general, $2^{\mathrm{a}}$ ed., Santiago, Edit. Jurídica de Chile, 2008. 
Politoff/Matus/Ramírez, Lecciones de Derecho penal chileno, Parte especial, $2^{a}$ ed., Santiago, Edit. Jurídica de Chile, 2007.

Robles, G., El Derecho como texto (Cuatro estudios de Teoría comunicacional del Derecho), Madrid, Civitas, 1998.

Robles, G., Las reglas del Derecho y las reglas de los juegos: ensayo de teoría analítica del derecho, Palma de Mallorca, Universidad, 1984.

Rodríguez Devesa/Serrano Gómez, Derecho Penal español. PG, $18^{\text {a }}$ ed., Madrid, Dykinson, 1995.

Roxin, C., Derecho Penal. PG I (trad. Luzón Peña/Díaz y García Conlledo/De Vicente Remesal), Madrid, Civitas, 1997.

Roxin, C., Política Criminal y Sistema del Derecho penal (trad. Muñoz Conde), Barcelona, Bosch, 1972.

Ruiz Sanz, M., "De la ciencia de la legislación hacia la técnica legislativa", en Anuario de Filosofía del Derecho XIV, 1997, pp. 637-650.

SAinz Moreno, F., "La técnica normativa: visión unitaria de una materia plural", en Corona Ferrero/Pau Vall/Tudela Aranda (coords.), La técnica legislativa a debate, Madrid, Tecnos, 1994, pp. 19-47.

Sainz Moreno/Da SiLva Ochoa, "Propuesta de directrices para mejorar la calidad de las leyes", en Sainz Moreno/Da Silva Ochoa (coords.), La calidad de las leyes, Vitoria, Parlamento Vasco, 1989, pp. 385-402.

SÁnChez-Vera Gómez-Trelles, J., Intervención omisiva, posición de garante y probibición de sobrevaloración del aporte, Bogotá, Universidad Externado de Colombia, 1995.

SCHÄFfER, H., "Racionalización y creación del Derecho" (trad. Montoro Chiner), en Documentación Administrativa 218-219, 1989, pp. 153-195.

SchünemanN, B., "Introducción al razonamiento sistemático en Derecho penal", en SchÜNEMANN (comp.), El sistema moderno del Derecho penal: cuestiones fundamentales (introducción, traducción y notas de Silva Sánchez), Madrid, Tecnos, 1991, pp. 31-80.

Silva SÁnchez, Aproximación al Derecho penal contemporáneo, Barcelona, Bosch, 1992.

Silva SÁnCHez, El delito de omisión: concepto y sistema, $2^{\mathrm{a}}$ ed., Buenos Aires, BdeF, 2003.

Tiedemann, K., Tatbestandsfunktionen im Nebenstrafrecht, Tübingen, 1969.

Tudela Aranda, "La legitimación competencial de las leyes y la técnica normativa", en Corona Ferrero/Pau Vall/Tudela Aranda (coords.), La técnica legislativa a debate, Madrid, Tecnos, 1994, pp. 83-120.

Vidales Rodríguez, C., La eficacia retroactiva de los cambios jurisprudenciales, Valencia, Tirant lo Blanch, 2001.

Vives Antón, en Cobo del Rosal (drg.), Comentarios al Código Penal, I, Madrid, Edersa, 1999.

Vives Antón, Fundamentos del sistema penal, Valencia, Tirant lo Blanch, 1996.

Vives Antón, T., "Dos problemas del positivismo jurídico", en La libertad como pretexto, Valencia, Tirant lo Blanch, 1995, pp. 135-159.

Wright, G. H. von, Norma y acción: una investigación lógica (trad. García Ferrero), Madrid, Tecnos, 1970.

WróBlewski, "Propos final", en AAVV, La Science de la Législation, Paris, Presses Universitaires de France, 1988, pp. 106-110. 